\title{
Promoção do aleitamento materno no ensino fundamental: revisão integrativa
}

\author{
Fernanda Demutti Pimpão Martins ${ }^{1}$, Luciana Pedrosa Leal ${ }^{2}$, Tatiane Gomes Guedes ${ }^{3}$, \\ Marly Javorski ${ }^{4}$, Cleide Maria Pontes ${ }^{5}$
}

\footnotetext{
${ }^{1}$ Enfermeira, Mestre em Enfermagem. Discente do Programa de Pós-Graduação em Enfermagem, nível Doutorado, da Universidade Federal de Pernambuco. Recife, PE, Brasil. E-mail: fhernandapimpao@yahoo.com.br.

${ }^{2}$ Enfermagem, Doutora em Nutrição. Professora Adjunta da Universidade Federal de Pernambuco. Recife, PE, Brasil. E-mail: lucianapleal@hotmail.com.

${ }^{3}$ Enfermagem, Doutora em Enfermagem. Professora Adjunta da Universidade Federal de Pernambuco. Recife, PE, Brasil. E-mail: tatigguedes@yahoo.com.br.

${ }^{4}$ Enfermagem, Doutora em Enfermagem. Professora Titular da Universidade Federal de Pernambuco. Recife, PE, Brasil. E-mail: marly.11@gmail.com.

${ }^{5}$ Enfermagem, Doutora em Nutrição. Professora Titular da Universidade Federal de Pernambuco. Recife, PE, Brasil. E-mail: cmpontes18@gmail.com.
}

Recebido: 19/04/2016.

Aceito: 29/09/2016.

\section{Como citar esse artigo}

Martins FDP, Leal LP, Guedes TG, Javorski $\mathrm{M}$, Pontes CM. Promoção do aleitamento materno no ensino fundamental: revisão integrativa. Rev. Eletr. Enf. [Internet]. 2016 [acesso em:______ Disponível em:

http://dx.doi.org/10.5216/ree.v18.40682.
Publicado: 22/12/2016.

\section{RESUMO}

Estudo com o objetivo de analisar as abordagens sobre a promoção do aleitamento materno no ensino fundamental. Revisão integrativa realizada na BVS, PUBMED, SCOPUS, CINAHL, COCHRANE e SciELO, sendo encontradas 1.598 publicações e sete selecionadas para a amostra final. Categorias identificadas - Abordagens sobre 0 conhecimento, percepções, crenças e experiências de aleitamento materno na perspectiva das crianças: as entrevistas revelaram conhecimentos e crenças desfavoráveis à amamentação; Abordagem do conteúdo de promoção do aleitamento materno no ensino fundamental: o conteúdo é abordado superficialmente nos livros didáticos e os educadores afirmam não ministrá-lo em aula. A abordagem da amamentação no ensino fundamental demonstrou-se variada, porém, reduzida, especialmente em relação às intervenções educativas. Ao enfermeiro cabe ampliar essa abordagem, com metodologias ativas e lúdicas, com vistas a impactar no futuro das próximas gerações.

Descritores: Aleitamento Materno; Promoção da Saúde; Ensino Fundamental e Médio; Enfermagem Obstétrica.

\section{INTRODUÇÃO}

Evidências reforçam os benefícios do aleitamento materno para redução da morbidade e mortalidade infantil, sendo comprovada a prevenção de infecções e de má oclusão dentária em crianças que são amamentadas por períodos mais longos. Os efeitos desta prática podem se estender para a vida adulta promovendo aumento da inteligência e diminuição do risco em desenvolver obesidade e diabetes. Na saúde da mulher, a amamentação protege 
contra o câncer de mama e de ovário, diabetes tipo 2 e prolonga o espaçamento entre as gestações. Essas vantagens se traduzem na redução dos gastos em serviços de saúde e têm reflexo na família, sociedade e meio ambiente, contribuindo para um mundo mais saudável, igualitário e sustentável ${ }^{(1-2)}$.

Mundialmente, cerca de $80 \%$ das crianças recebem leite materno no primeiro ano de vida, porém, aproximadamente metade delas é amamentada na primeira hora após o nascimento. Em relação ao aleitamento exclusivo, na maioria dos países, as taxas estão abaixo de $50 \%$, indicando que esforços devem ser empreendidos na promoção da amamentação, especialmente, no início precoce e na manutenção exclusiva $^{(1-2)}$.

Além dos programas e políticas de incentivo, proteção e suporte à amamentação, as estratégias para fomentar essa prática precisam ser ampliadas e contemplar a mobilização social, os meios de comunicação, o aconselhamento e apoio à lactação na conjuntura da família e da comunidade. O sucesso do aleitamento materno não deve ser visto como uma responsabilidade única da mulher, mas sim coletiva da sociedade ${ }^{(2)}$.

A importância desta prática deve ser enfatizada desde cedo, bem antes do pré-natal, de forma a facilitar a construção de atitudes e comportamentos positivos sobre o aleitamento materno ${ }^{(3)}$ visto que a decisão do tipo de alimentação infantil, em geral, é realizada antes da gravidez. Nesse contexto, a escola é um cenário propício para ações de promoção à saúde e, por isso, deveria expor a todos os estudantes as vantagens do aleitamento materno durante os anos de formação. Atividades educativas voltadas aos escolares promovem atitudes mais favoráveis à amamentação ${ }^{(4)}$ e podem contribuir para a motivação em amamentar ao se tornarem pais ${ }^{(5)}$. Ademais, a instituição educacional tem o potencial de integrar diversos atores da sociedade: mulher, crianças, adolescentes, educadores, família e profissionais da saúde no mesmo local ${ }^{(6)}$.

No Brasil, o Programa Saúde na Escola lançado em 2007 vem reforçar o papel essencial das enfermeiras na educação escolar, em parceria entre escolas e unidades básicas de saúde. A intenção é criar espaços dialógicos que favoreçam o aprendizado sobre saúde não se restringindo apenas ao ambiente físico da instituição, mas contemplando a realidade da comunidade de maneira a englobar a família e trazê-la para perto da escola e dos profissionais da saúde ${ }^{(7)}$.

Os professores do ensino fundamental, contudo, sentem-se inseguros para realizar ações de promoção à saúde na escola, relatam dificuldades em articular parceria com os profissionais da saúde nas atividades de planejamento, execução e avaliação, e destacam a abordagem resumida sobre saúde nos livros didáticos ${ }^{(8)}$.

No ensino médio, a inclusão do conteúdo de aleitamento materno no currículo é vista como importante na ótica de professores e enfermeiros ${ }^{(9)}$. Nesse sentido, intervenções educativas realizadas com adolescentes do ensino médio demonstram efeitos positivos no aumento do conhecimento dos jovens acerca desta temática. No entanto, os estudos ressaltam a necessidade de maiores pesquisas para avaliar as implicações futuras dessas intervenções na prática da amamentação ${ }^{(10)}$.

Desde o período que antecede a gravidez até o pós-parto, vários sistemas interagem para garantir o sucesso da amamentação, incluindo o suporte familiar, profissional, político, econômico e legal à mulher. 
Nesse contexto, a escola tem sido citada como ambiente propício à discussão do aleitamento materno ${ }^{(9)}$. Em geral, as atividades educativas são direcionadas ao público adolescente, tendo em vista a possibilidade da ocorrência de gravidez nessa faixa etária. Nota-se que a abordagem desse conteúdo durante a infância, especialmente no ambiente escolar, não é citada nesses estudos.

Portanto, conhecer a produção do conhecimento científico acerca da promoção da amamentação no ensino fundamental possibilitará identificar possíveis lacunas e direcionar novas pesquisas que contribuam para o planejamento de atividades intersetoriais com articulação entre educadores e profissionais da saúde em prol do aleitamento materno. Assim, esse estudo tem como objetivo analisar as abordagens sobre a promoção do aleitamento materno no ensino fundamental.

\section{MÉTODO}

Revisão integrativa da literatura, cuja finalidade é resumir o conhecimento de um determinado assunto bem como produzir o máximo de conhecimentos novos, os quais não foram abordados ou aprofundados em pesquisas anteriores. Para tanto, seguiram-se as cinco etapas propostas por Cooper ${ }^{(11)}$.

Para a primeira etapa, formulou-se a questão de pesquisa: Como é abordada a promoção do aleitamento materno no ensino fundamental? Na segunda etapa, coleta de dados, foram escolhidas as bases: Literatura Latino-Americana e do Caribe (LILACS), Base de Dados de Enfermagem (BDENF), Índice Bibliográfico Espanhol de Ciências da Saúde (IBECS), U.S. National Library of Medicine (PubMed), Medical Literature Analisys and Retrieval System Online (MEDLINE), SCOPUS, Cumulative Index to Nursing and Allied Health Literature (CINAHL), COCHRANE e a biblioteca virtual da Scientific Electronic Library Online (SciELO).

Os seguintes cruzamentos foram realizados com os Descritores em Ciências da Saúde (DeCS) e os respectivos termos do Medical Subject Headings (MESH) com o operador boleano "and": 1ㅇ) "Aleitamento materno"/"Breastfeeding", "Educação em saúde"/"Health education”, "Criança”/“Child”; $2^{\circ}$ ) "Aleitamento materno" /"Breastfeeding", "Ensino fundamental e médio"/"Primary school"; 3) "Aleitamento

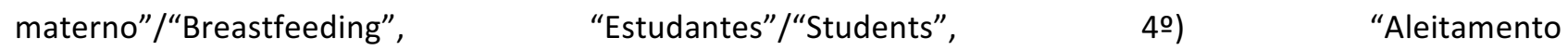
materno"/"Breastfeeding"/"Promoção da saúde"/"Health promotion"/"Criança"/"Child".

No idioma português, optou-se por utilizar o descritor 'Ensino fundamental e médio' porque não havia o descritor que abordasse somente o termo 'ensino fundamental'. Já no MESH foi encontrado o descritor exato 'Primary school'. A busca e a coleta bibliográfica foram realizadas na segunda quinzena de outubro de 2015.

Na terceira etapa, avaliação dos dados, foram considerados os critérios de inclusão: abordar a temática de promoção do aleitamento materno no ensino fundamental; ter como participantes escolares e/ou o cenário da escola; artigo original; idiomas português, inglês e espanhol; artigo com resumo e texto completo, disponível na íntegra ou obtido por meio da comutação na instituição de ensino. Ressalta-se que os estudos desenvolvidos no ensino médio foram incluídos na revisão somente quando contemplavam também o ensino fundamental. Na tentativa de ampliar a busca não foi estabelecido limite temporal para seleção dos artigos. 
Os critérios de exclusão foram: dissertações, teses, manuais, editoriais, artigos reflexivos ou de revisão de literatura/integrativa/sistemática e os estudos que abordavam somente a etapa do ensino médio. Inicialmente, foram localizados 1.598 estudos (Tabela 1).

Tabela 1: Publicações encontradas sobre promoção do aleitamento materno no ensino fundamental. Recife, PE, Brasil, 2015.

\begin{tabular}{cccccc}
\hline $\begin{array}{c}\text { Cruzamento/Bases } \\
\text { de dados/Biblioteca }\end{array}$ & $\begin{array}{c}\text { Aleitamento } \\
\text { materno/Educação } \\
\text { em Saúde/Criança }\end{array}$ & $\begin{array}{c}\text { Aleitamento } \\
\text { materno/Ensino } \\
\text { Fundamental e } \\
\text { médio }\end{array}$ & $\begin{array}{c}\text { Aleitamento } \\
\text { materno/estudantes }\end{array}$ & $\begin{array}{c}\text { Aleitamento } \\
\text { materno/Promoção } \\
\text { da saúde/Criança }\end{array}$ & $\begin{array}{c}\text { Total } \\
\text { LILACS }\end{array}$ \\
IBECS & 08 & 01 & 02 & 16 & 27 \\
BDENF & 0 & 0 & 0 & 0 & 0 \\
MEDLINE & 0 & 0 & 0 & 1 & 1 \\
SCIELO & 52 & 0 & 37 & 100 & 189 \\
PUBMED & 05 & 01 & 08 & 27 & 41 \\
SCOPUS & 152 & 62 & 51 & 186 & 473 \\
CINAHL & 321 & 52 & 07 & 266 & 690 \\
COCHRANE & 07 & 0 & 13 & 34 & 48 \\
\hline Total & 51 & 07 & $\mathbf{1 9 1}$ & & $\mathbf{6 8 8}$ \\
\hline
\end{tabular}

Após a leitura de título e resumo, foram excluídos 1.590 artigos, destes 1.540 por estarem inadequados à temática e 32 por se encontrarem repetidos nas bases de dados, sendo contabilizados somente uma vez (Figura 1). Salienta-se que essa etapa foi realizada independente por um avaliador e as dúvidas, quando houveram, foram discutidas com os demais autores. Oito artigos foram pré-selecionados e submetidos ao processo de avaliação do rigor metodológico por meio do formulário padronizado do Critical Appraisal Skills Programme (CASP) $)^{(12)}$ adaptado para contemplar todos os desenhos de estudo presente na amostra. Este check-list contempla 10 questões, para cada uma delas pode ser atribuída a resposta/pontuação: sim (1 ponto); em parte (0 ponto); não (0 ponto), com score entre zero à dez. A pontuação igual ou superior a seis (classificação $A$ ) indica que o estudo deve ser incluído na revisão, enquanto que a pontuação igual ou inferior a cinco (classificação B) caracteriza baixo rigor metodológico. Nessa etapa, um estudo foi excluído, pois obteve pontuação inferior a cinco, sendo a amostra final composta por sete estudos.

Para a quarta etapa, análise e interpretação, utilizou-se o instrumento construído e validado por Ursi $^{(13)}$, adaptado, para reunir e sintetizar as informações referentes à promoção do aleitamento materno no ensino fundamental: nome da pesquisa; autoria; periódico de publicação; instituição; ano de publicação; objetivos do estudo; detalhamento metodológico; características da amostra; nível de evidência; resultados; recomendações e conclusões. A síntese e interpretação dos estudos foi discutida entre três avaliadores durante várias reuniões com vistas a esclarecer as informações de cada pesquisa e responder ao objetivo da revisão. $O$ nível de evidência foi identificado segundo Stillwell et al ${ }^{(14)}$ :

1. Revisões sistemáticas ou metanálise,

2. Ensaio clínico randomizado,

3. Ensaio clínico sem randomização, 
4. Caso controle ou estudo de coorte,

5. Revisão sistemática de estudos qualitativos ou descritivos,

6. Estudos qualitativos ou descritivos

7. Opiniões ou consensos de especialistas.

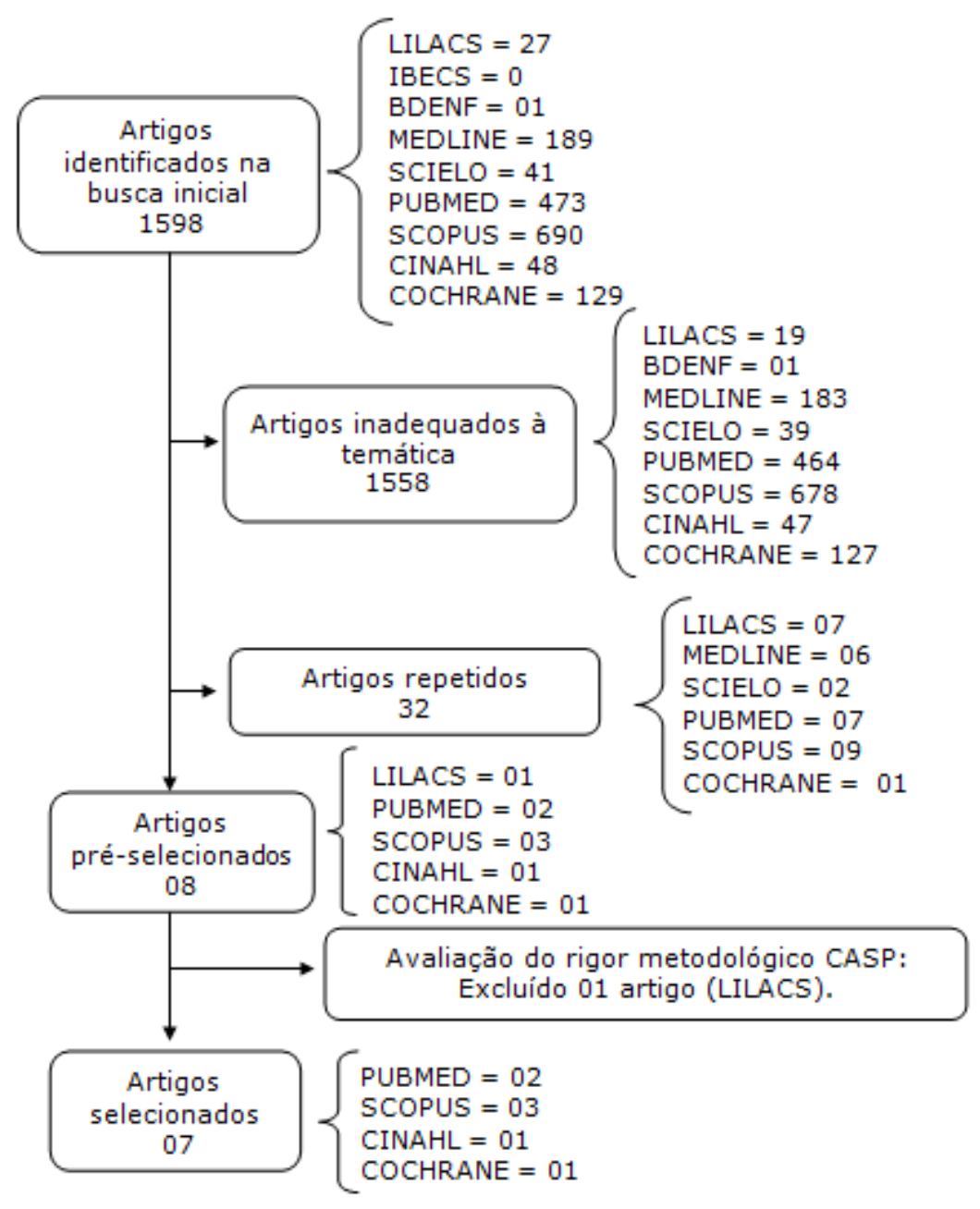

Figura 1: Fluxograma de seleção dos artigos.

Os resultados foram discutidos entre três avaliadores e submetidos à análise de conteúdo ${ }^{(15)}$, na modalidade temática, que contempla as etapas de pré-análise, exploração do material ou codificação e tratamento ou interpretação dos resultados. A primeira etapa compreende a leitura flutuante, a constituição do corpus e a formulação e reformulação de hipóteses. Na codificação do material, busca-se encontrar expressões ou palavras significativas para nortear a construção das categorias. Por fim, procede-se a interpretação dos resultados. A quinta etapa, apresentação dos resultados, foi realizada a partir da descrição das categorias identificadas e discussão fundamentada em estudos da área.

\section{RESULTADOS}

O período de publicação variou de 2008 à $2013^{(16-22)}$, cinco estudos foram identificados com nível de evidência $6^{(16,19-22)}$, e dois com nível $2^{(17-18)}$. Quanto ao idioma, quatro são publicações em inglês ${ }^{(17-20)}$ e três 
em português ${ }^{(16,21-22)}$. O local de pesquisa predominante foi o Brasil( ${ }^{(16-18,22)}$.

Em relação ao delineamento metodológico, quatro optaram pela abordagem quantitativa ${ }^{(16-18,20)}$ e três utilizaram a qualitativa ${ }^{(19,21-22)}$. O método de coleta variou de questionário contendo questões sobre vantagens/desvantagens e participação paterna na amamentação(16), ensino da amamentação(20); intervenção educativa por meio de palestra, utilizando recursos visuais e slides com imagens ${ }^{(17)}$, com o uso de vídeo, seguido da discussão de conceitos, encenação da história de alimentação das crianças, folheto para colorir e escrever a história de amamentação, e aplicação de questionário pré/pós-teste ${ }^{(18)}$. A técnica participativa de história contada foi mencionada em um estudo ${ }^{(19)}$, consistindo na interpretação das crianças sobre uma narrativa de alimentação do recém-nascido criada por elas, com auxílio de desenhos e texto. Outra forma de coleta de dados foi a consulta nos manuais ${ }^{(21)}$, programas curriculares e livros escolares do ensino fundamental ${ }^{(22)}$ para verificar o conteúdo de amamentação.

A partir da leitura e releitura dos artigos foram identificadas duas categorias temáticas em relação à promoção do aleitamento materno no ensino fundamental (Figura 2).

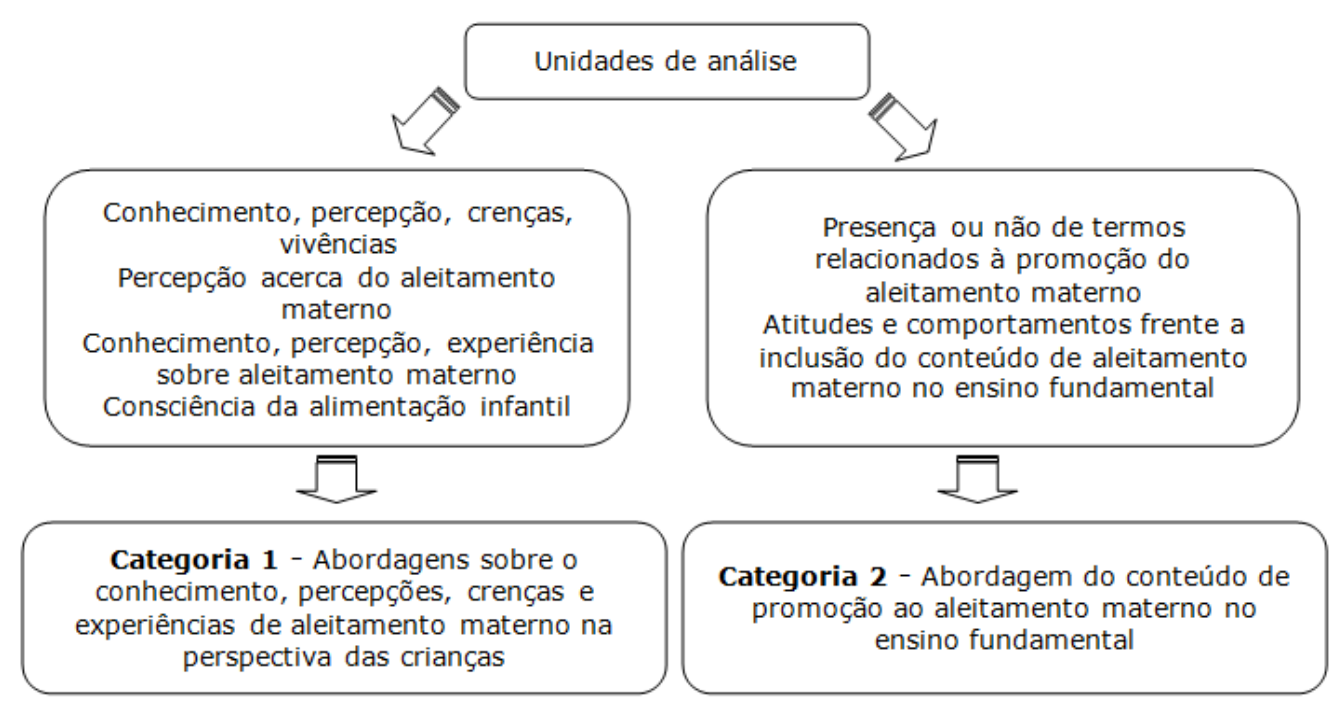

Figura 2: Fluxograma do processo de categorização dos artigos.

Na primeira categoria, Abordagens sobre o conhecimento, percepções, crenças e experiências de aleitamento materno na perspectiva das crianças, foram identificados quatro artigos ${ }^{(16-19)}$, tendo como $^{2}$ amostra os escolares do ensino fundamental.

A segunda, Abordagem do conteúdo de promoção do aleitamento materno no ensino fundamental, composta por três estudos ${ }^{(20-22)}$, caracteriza-se por entrevistas com professores e enfermeiros e consultas aos manuais, programas e livros curriculares. Ressalta-se que um dos estudos ${ }^{(20)}$ desta categoria contemplava ambas as etapas de ensino, fundamental e médio, sendo por esse motivo incluído na amostra.

A síntese das informações (autoria, bases de dados, objetivos, método) e principais resultados extraídos dos artigos de acordo com as categorias identificadas encontra-se descrita no Quadro 1. 
Quadro 1: Descrição dos artigos sobre 'Promoção do aleitamento materno no ensino fundamental' quanto à autoria,

base de dados, objetivos, método e principais resultados segundo as categorias identificadas.

\begin{tabular}{|c|c|c|c|}
\hline $\begin{array}{c}\text { Autoria/Base de } \\
\text { dados }\end{array}$ & Objetivos & Delineamento/amostra/local & Resultados \\
\hline \multicolumn{4}{|c|}{ Categoria 1: Abordagens sobre o conhecimento, percepções, crenças e experiências de aleitamento materno na perspectiva das crianças. } \\
\hline $\begin{array}{c}\text { Bottaro S, Giugliani } \\
\text { ERJ }^{(16)}\end{array}$ & \multirow[b]{3}{*}{$\begin{array}{l}\text { Avaliar conhecimentos, percepções, crenças e } \\
\text { vivências sobre o aleitamento materno em escolares } \\
\text { de ambos os sexos do Ensino Fundamental. }\end{array}$} & Transversal. & \multirow{3}{*}{$\begin{array}{l}\text { Pouco conhecimento quanto à duração do aleitamento materno e } \\
\text { alimentação complementar; crenças (uso de chás, água, chupeta; leite } \\
\text { fraco; tamanho da mama X produção do leite); meninos não associaram } \\
\text { a amamentação como primeira função da mama e foram contrários a } \\
\text { prática em público; maioria foi amamentada e presenciou situação de } \\
\text { aleitamento materno; as meninas referiram amamentar bonecas } \\
\text { durante brincadeiras }(41,7 \%) \text { e os meninos pouco participaram disso } \\
(16,6 \%) .\end{array}$} \\
\hline \multirow[b]{2}{*}{ SCOPUS } & & 564 escolares ( $5^{\text {a }}$ série). & \\
\hline & & Rio Grande do Sul, Brasil. & \\
\hline \multirow{2}{*}{$\begin{array}{l}\text { Fujimori M, Morais } \\
\text { TC, França EL, } \\
\text { Toledo OR, } \\
\text { Honório-França } \\
\quad \mathrm{AC}^{(17)} \\
\end{array}$} & \multirow{3}{*}{$\begin{array}{l}\text { Avaliar a percepção de estudantes do ensino } \\
\text { fundamental em relação ao aleitamento materno e a } \\
\text { influência de palestra educativa sobre seus } \\
\text { conhecimentos. }\end{array}$} & Transversal. & \multirow{3}{*}{$\begin{array}{l}\text { Maioria tinha intenção de ter filhos e amamentá-los ou apoiar esposas } \\
\text { na decisão; mais de } 30 \% \text { das crianças de ambos os sexos relataram } \\
\text { constrangimento acerca da amamentação em público; maioria recebeu } \\
\text { informação prévia sobre aleitamento materno ( } 28 \% \text { nas escolas) e } \\
\text { gostaria de aprender mais; intervenção exerceu efeito positivo quanto à } \\
\text { praticidade do aleitamento materno, uso de chupeta e período para } \\
\text { complementação alimentar, sendo que os meninos assimilaram mais as } \\
\text { vantagens da amamentação em comparação com as meninas. }\end{array}$} \\
\hline & & 503 estudantes ( $4^{\mathrm{a}}$ à $8^{\mathrm{a}}$ série). & \\
\hline SCOPUS & & Mato Grosso, Brasil. & \\
\hline $\begin{array}{c}\text { Bottaro SM, } \\
\text { Giugliani ERJ }^{(18)}\end{array}$ & \multirow{3}{*}{$\begin{array}{c}\text { Avaliar a efetividade e o efeito residual de uma } \\
\text { intervenção educacional para melhorar o } \\
\text { conhecimento e as atitudes acerca da amamentação } \\
\text { entre crianças da quinta série de ambos os sexos no } \\
\text { Brasil. }\end{array}$} & Ensaio clínico randomizado & \multirow{3}{*}{$\begin{array}{l}\text { A maioria foi amamentada e presenciou situação de aleitamento } \\
\text { materno; } 41,7 \% \text { das meninas brincaram de amamentar suas bonecas e } \\
16,6 \% \text { dos meninos participaram desse tipo de atividade; intervenção } \\
\text { foi positiva tendo maior impacto nas meninas na faixa etária de } 9 \text { a } 11 \\
\text { anos e foi mais evidente nos estudantes das escolas públicas. }\end{array}$} \\
\hline \multirow[t]{2}{*}{ COCHRANE } & & $\begin{array}{l}564 \text { estudantes de escolas públicas, } \\
\text { privadas e rurais ( } 298 \text { grupo } \\
\text { intervenção e } 253 \text { grupo controle), } 5 \text { a } \\
\text { série. }\end{array}$ & \\
\hline & & Rio Grande do Sul, Brasil. & \\
\hline \multirow{2}{*}{$\begin{array}{l}\text { Angell C, Alexander } \\
\mathrm{J}, \text { Hunt } \mathrm{JA}^{(19)}\end{array}$} & \multirow[b]{3}{*}{$\begin{array}{l}\text { Explorar a consciência da alimentação infantil em } \\
\text { crianças do ensino fundamental. }\end{array}$} & Qualitativo. & \multirow{3}{*}{$\begin{array}{c}\text { Menos da metade das crianças referenciou a amamentação na } \\
\text { dinâmica de "Draw, write and tell" quanto a maneira de alimentação do } \\
\text { bebê, e aquelas que referenciaram, colocaram como segunda opção ou } \\
\text { uma alternativa extra de alimentação; a maioria ilustrou a fórmula do } \\
\text { leite e detalhou as práticas com mamadeiras, além de incluir uma } \\
\text { variedade de alimentos sólidos. }\end{array}$} \\
\hline & & 56 crianças (de 5 a 11 anos). & \\
\hline PUBMED & & Inglaterra, Reino Unido. & \\
\hline
\end{tabular}

Rev. Eletr. Enf. [Internet]. 2016 [acesso em:_/_/_];18:e1198. Disponível em: http://dx.doi.org/10.5216/ree.v18.40682. 


\begin{tabular}{|c|c|c|c|}
\hline $\begin{array}{l}\text { Autoria/Base de } \\
\text { dados }\end{array}$ & Objetivos & Delineamento/amostra/local & Resultados \\
\hline \multicolumn{4}{|c|}{ Categoria 2: Abordagem do conteúdo de promoção do aleitamento materno no ensino fundamental. } \\
\hline Spear $\mathrm{HJ}^{(20)}$ & \multirow{4}{*}{$\begin{array}{l}\text { Explorar atitudes e comportamentos de enfermeiros } \\
\text { educadores e professores do ensino fundamental e } \\
\text { médio relacionados à inclusão de conteúdos sobre } \\
\text { aleitamento materno. }\end{array}$} & Descritivo transversa & \multirow{4}{*}{$\begin{array}{l}\text { Professores das escolas reconheceram a importância da inclusão do } \\
\text { conteúdo dos benefícios da amamentação no currículo escolar, no nível } \\
\text { superior e médio; a maioria afirmou não abordar esse conteúdo em } \\
\text { aula; as justificativas para não ministrar esse conteúdo são: não faz } \\
\text { parte do currículo escolar, falta de tempo e de instrumentalização; } \\
\text { cerca de 15\% afirmou ensinar os benefícios da amamentação. }\end{array}$} \\
\hline \multirow{3}{*}{ SCOPUS } & & 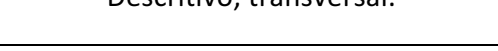 & \\
\hline & & $\begin{array}{l}107 \text { professores (48 enfermeiros e } 59 \\
\text { professores do ensino fundamental e } \\
\text { médio). }\end{array}$ & \\
\hline & & Virginia, Estados Unidos. & \\
\hline \multirow{2}{*}{$\begin{array}{l}\text { Galvão DMPG, Silva } \\
\qquad \mathrm{IA}^{(21)}\end{array}$} & \multirow{3}{*}{$\begin{array}{l}\text { Conhecer como a amamentação é abordada às } \\
\text { crianças do 10 Ciclo, e o que aprendem na escola } \\
\text { sobre este tema. }\end{array}$} & Descritivo, qualitativo. & \multirow{3}{*}{$\begin{array}{l}\text { Conteúdo sobre promoção do aleitamento materno identificado em } \\
\text { apenas dois manuais do } 3 \text { o ano; presença de textos e imagens que } \\
\text { fazem alusão à cultura da alimentação artificial (chupeta, mamadeira, } \\
\text { criança tomando leite com mamadeira entre a família). }\end{array}$} \\
\hline & & $\begin{array}{l}19 \text { manuais escolares do } 10 \text { ao } 40 \text { ano } \\
\text { do ensino fundamental. }\end{array}$ & \\
\hline CINAHL & & Coimbra, Portugal. & \\
\hline $\begin{array}{l}\text { Galvão DMPG, Silva } \\
\qquad \text { IA }^{(22)} \\
\text { PUBMED }\end{array}$ & $\begin{array}{l}\text { Analisar os programas curriculares definidos para os } \\
\text { primeiros anos na disciplina de Ciências do Ensino } \\
\text { Fundamental e os conteúdos dos livros escolares } \\
\text { adotados nessa disciplina em estabelecimentos } \\
\text { brasileiros de ensino público quanto à presença ou } \\
\text { não de termos relacionados à prática da } \\
\text { amamentação. }\end{array}$ & $\begin{array}{l}\text { Descritivo, qualitativo. } \\
\text { Programas curriculares e livros } \\
\text { escolares das disciplinas do } 20 \text { ao } 50 \\
\text { ano. } \\
\text { São Paulo, Brasil. }\end{array}$ & $\begin{array}{l}\text { Conteúdos não identificados nos livros e manuais escolares: fisiologia } \\
\text { da lactação, uso da chupeta e mamadeira como prática inadequada; } \\
\text { imagens identificadas: chupeta e mamadeira; conteúdos favoráveis ao } \\
\text { aleitamento materno identificados: alimentação dos mamíferos, início } \\
\text { da amamentação logo após o nascimento, período da amamentação, } \\
\text { importância do pai, apoio da família, vantagens do aleitamento } \\
\text { materno para mãe, bebê, família e sociedade, e contraindicações ao uso } \\
\text { de água e alimentação artificial. }\end{array}$ \\
\hline
\end{tabular}




\section{DISCUSSÃO}

Os estudos apresentaram abordagens diversificadas sobre promoção do aleitamento materno no ensino fundamental, desde entrevistas ${ }^{(16-17,20)}$ com crianças, professores e enfermeiros, intervenções educativas voltadas para os escolares ${ }^{(17-18)}$ até a consulta em programas e manuais curriculares ${ }^{(21-22)}$.

As entrevistas com as crianças revelaram um conhecimento inadequado sobre aleitamento materno visto que fazem alusão frequente ao uso da alimentação infantil com mamadeira e possuem crenças não favoráveis a prática da amamentação. Escolares de Londres, entre 13 e 15 anos, também demonstraram conhecimento similar ao afirmar que a mamadeira tem benefícios para a saúde do bebê apesar de terem previamente concordado sobre as vantagens do leite materno. Essa visão confusa pode advir das campanhas publicitárias sobre o uso da mamadeira com leite ordenhado ou dos fabricantes de fórmulas lácteas que defendem o leite industrializado para o crescimento e desenvolvimento infantil ${ }^{(5)}$.

A introdução precoce de leite industrializado e/ou outros alimentos antes dos seis meses de vida da criança é uma prática comum entre as mães por acreditarem que seu leite é fraco e não supre as necessidade nutricionais do seu filho. A oferta de água ao bebê é justificada pelas mães devido ao leite materno ser incapaz de saciar a sede da criança ${ }^{(23)}$. Esse desconhecimento das mulheres pode estar influenciando no aprendizado das crianças à medida que elas repetem as crenças e mitos acerca da amamentação que presenciam no seu convívio social. O conhecimento insuficiente e as crenças são fatores que podem levar ao desmame precoce.

Esclarecimentos de mitos e crenças como leite fraco e pouco leite são fundamentais para tornar as mulheres mais seguras na prática da amamentação ${ }^{(24)}$. Essa atitude de segurança poderá refletir no processo de amamentação e consequentemente no ensino e aprendizagem das crianças sobre o ato de aleitar.

Os escolares que recebem educação informal sobre aleitamento materno ou têm contato com esta prática por meio do convívio social ou da televisão apresentam atitudes mais positivas ao aleitamento materno, sobretudo, as meninas quando comparadas com os meninos. Em vista disso, as diferenças de gênero devem ser consideradas no planejamento das atividades educativas incluindo os meninos para que eles conheçam a maneira como podem apoiar as mulheres no processo de aleitamento materno. 0 menino poderá ser no futuro pai e ter um papel significativo na escolha do tipo de alimentação infantil( ${ }^{(4)}$.

Com relação aos meninos, os resultados revelaram percepções contraditórias, desde a pretensão de apoiar a mulher na decisão de aleitar até constrangimento com a amamentação em público. Escolares de 13 a 15 anos de ambos os sexos do ensino primário de Londres também demonstram resistência ao ato de amamentar na presença de outras pessoas, caracterizando essa situação como inaceitável ou embaraçosa e desconfortável para a mãe ${ }^{(5)}$. Nesse contexto, infere-se que a prática da amamentação, embora fisiológica e inegavelmente benéfica à mulher, à criança, à sociedade e ao meio ambiente, parece estar se distanciando de ser um ato natural para ser percebida como algo constrangedor.

A percepção dos meninos em relação à amamentação merece destaque, pois eles poderão estar envolvidos com esta prática na condição de pai ou como homem na sociedade. Evidências indicam que o 
suporte do companheiro à mulher pode exercer influência significativa para o início do processo de aleitar ${ }^{(25)}$, sendo um fator relevante para a confiança da mulher na decisão e na continuidade do aleitamento materno. Quando o companheiro percebe a importância dessa prática estimula a mulher por meio de palavras de incentivo, auxílio nos cuidados com o bebê e até com ajuda para melhor posicioná-lo durante a amamentação(26).

Estratégias para promoção do aleitamento materno com os pais no ciclo gravídico-puerperal têm efeito positivo no aumento das taxas de amamentação e, por isso, tem sido incentivado maior envolvimento do companheiro nas ações de educação em saúde desde o pré-natal ${ }^{(27)}$. Essa participação do homem nos cuidados com a mulher, principalmente durante a amamentação, pode começar a ser trabalhada desde a infância. Os momentos lúdicos podem ser uma oportunidade para discutir a maneira como os bebês devem ser alimentados durante as brincadeiras. Talvez essas pequenas atitudes contribuam para que os meninos se tornem adultos mais conscientes do seu papel no apoio à mulher durante o aleitamento materno e percebam esse ato com maior naturalidade.

Nesse sentido, a abordagem sobre o aleitamento materno pode ser benéfica quando iniciada desde cedo, para ambos os sexos, tanto no convívio da família quanto na escola porque são os espaços privilegiados para o aprendizado e desenvolvimento do infante. E apesar das crianças receberem informações acerca do aleitamento $^{(18)}$, o cenário escolar contribui muito pouco. Isso pode demonstrar a necessidade de capacitação dos professores para lidar com essa temática ou mesmo de aproximar o enfermeiro das ações de educação em saúde na escola.

As intervenções educativas, embora tenham atingido efeito positivo no aprendizado das crianças, foram realizadas de maneiras diferentes. Enquanto uma utilizou a palestra ${ }^{(17)}$ na perspectiva da metodologia tradicional, outra fez uma abordagem mais participativa, com o uso de vídeo e dramatização ${ }^{(18)}$. A técnica do desenho da história contada ${ }^{(19)}$ como método de coleta de dados também incentivou a participação das crianças, embora não houvesse a finalidade de ser uma atividade educativa.

O incentivo à participação dos escolares nas atividades de educação em saúde envolve a identificação de abordagens atrativas de acordo com o contexto local. A seleção de metodologias deve iniciar com o contato entre a equipe de saúde e a pedagógica para em conjunto definirem as estratégias mais adequadas ao público-alvo. Existe uma diversidade de métodos que podem ser desenvolvidos os conteúdos de saúde, desde palestras, oficinas, teatros, dança, música e jogos ${ }^{(28)}$.

Os professores são os agentes privilegiados no processo educativo, pois, teoricamente, possuem a instrumentalização necessária para que o aprendizado aconteça de maneira significativa para a criança. E, apesar da escola ter pouca participação na promoção do aleitamento materno, os escolares expressaram vontade em aprender mais acerca do assunto ${ }^{(17)}$, o que pode ser visto como positivo e reforça a necessidade de maior participação da escola nesse processo.

Estudo $^{(10)}$ realizado com adolescentes entre 12 e 13 anos de idade na Irlanda demonstrou que as intervenções educativas têm efeito positivo nas atitude moral, nas normas subjetivas, e na intenção das 
meninas em amamentar. Porém, os efeitos positivos para os meninos foram apenas com relação à construção do conhecimento sobre aleitamento materno.

Os autores ${ }^{(10)}$ descrevem explicações plausíveis para esse resultado referentes à intervenção e à imagem da amamentação como ato exclusivamente feminino. No caso dos meninos, a intervenção pode não ter atingido as necessidades deles quanto ao aprendizado sobre o aleitamento materno. Além disso, a ideia do homem apoiar uma parceira na amamentação pode parecer uma realidade muito distante para as crianças do sexo masculino.

O fato de os meninos serem menos receptivos ao ensino do aleitamento materno pode decorrer de uma cultura que não valoriza a participação do homem nessa prática. No entanto, o apoio positivo do companheiro é um preditor significativo na autoeficácia da mulher para amamentar ${ }^{(26)}$. Assim, estender o ensino da amamentação para além dos seus benefícios, e incluir outros membros da rede social, especialmente, o companheiro é fundamental para promoção do aleitar.

A questão de gênero manifesta-se também nas diferenças de opinião das crianças quanto à inclusão da temática do aleitamento materno no ensino fundamental, percebida de maneiras ambivalentes. Algumas meninas referiram que o conteúdo deveria ser ensinado à medida que há interesse em saber mais sobre o assunto. Outras acreditavam que a escola não é espaço para abordar a amamentação uma vez que a gravidez nessa idade não deve acontecer. Para os meninos, alguns consideraram que o ensino do aleitamento materno é mais relevante para as meninas, enquanto outros pensam que cabe à escola decidir sobre o que deve ser ensinado ${ }^{(5)}$.

De fato, a escola como instituição educacional tem o poder de decidir sobre os conteúdos a serem incluídos no programa escolar e os resultados dos estudos desta revisão evidenciaram inúmeros aspectos em relação ao aleitamento materno que precisam ser esclarecidos às crianças.

Nos artigos analisados, o conteúdo de aleitamento materno foi abordado de maneira superficial nos manuais do $1^{\circ}$ ao $4^{\circ}$ ano da rede de ensino pública de Coimbra, em Portugal ${ }^{(21)}$. Nos livros didáticos do $2^{\circ}$ ao $4^{\circ}$ ano dos escolares de São Paulo ${ }^{(22)}$, apesar de serem constatados conteúdos favoráveis à amamentação, foram identificadas imagens de chupeta e mamadeira. Essas ilustrações podem reforçar uma prática comumente presenciada pelas crianças e consequentemente reproduzida nas brincadeiras de infância. Esse resultado é preocupante devido o uso de chupeta ser fator de risco para interrupção do aleitamento materno exclusivo $^{(29)}$ e o uso de bicos artificiais (chupeta e mamadeira) estar associado à ausência de aleitamento no segundo semestre de vida da criança ${ }^{(30)}$.

A reduzida abordagem da temática de saúde também foi constatada nos livros didáticos de ciências destinados a alunos do $2^{\circ}$ ao $5^{\circ}$ ano do ensino fundamental em Uruguaiana, no Rio Grande do Sul. Predomina o enfoque na discussão de doenças, distanciando-se da ideia de "saúde" enquanto tema transversal proposto pelos Parâmetros Curriculares Nacionais ${ }^{(31)}$.

No material didático destinado aos escolares do ensino fundamental de São Paulo foram identificados aspectos de promoção à saúde relacionados ao conteúdo de alimentação e nutrição, especialmente nas 
disciplinas de História, Geografia, Ciências e Língua Portuguesa. Todavia, alguns conteúdos foram inconsistentes devido a presença de "situações de aprendizagem", as quais indicam temas e sugestões de atividades de ensino. A seleção do conteúdo fica sob responsabilidade do professor e do aluno, o que inviabiliza avaliar a qualidade dos conceitos. Além disso, pode dificultar a tarefa do professor à medida que essa atividade, por vezes, exige conhecimentos distantes da sua área de formação ${ }^{(32)}$.

Em relação à amamentação, a pouca ou inadequada referência à temática nos livros didáticos pode reforçar a dificuldade e insegurança do professor em abordar o conteúdo no seu programa escolar, ainda que reconheçam a relevância em ministrá-lo na educação básica ${ }^{(20)}$.

As ações de promoção à saúde nas escolas, na maioria das vezes, são iniciativas pontuais, isoladas, desvinculadas do currículo escolar e desarticuladas do projeto pedagógico da instituição. A ausência de intencionalidade dos professores nas atividades educativas em saúde desperdiça oportunidades que poderiam ser ricas para construção do conhecimento do estudante ${ }^{(8)}$.

Os professores destacam várias necessidades de promoção à saúde que podem ser trabalhadas com o apoio da equipe de saúde da família por meio de ações diversas como palestras, oficinas, dinâmicas, feiras de saúde e debates. No entanto, o sucesso da educação em saúde no âmbito escolar depende, dentre outros fatores, da integração da equipe de saúde com os profissionais da educação e da efetivação da intersetorialidade ${ }^{(28)}$. A promoção do aleitamento materno na escola precisa ser visualizada como objetivo comum da saúde e da educação para avançar no processo de ensino-aprendizado das crianças e contribuir para a formação de adultos mais conscientes acerca da amamentação como prática natural e mais adequada de alimentação infantil.

\section{CONCLUSÃO}

A abordagem metodológica do aleitamento materno no ensino fundamental nesta revisão foi predominantemente descritiva, direcionada principalmente às crianças, porém com reduzido número de intervenções educativas. Os artigos indicaram pouco uso de metodologias ativas e inadequado conhecimento dos escolares sobre a temática. A inserção do aleitamento materno no planejamento das atividades pedagógicas não é frequente, além disso, os livros didáticos têm pouca referência a esse conteúdo e, algumas vezes, trazem informações incorretas.

Os estudos indicaram que lacunas precisam ser preenchidas quanto à promoção do aleitamento materno no ensino fundamental, desde a preparação dos educadores para ministrar esse assunto, adequação dos instrumentos didáticos indicados pelos órgãos oficiais educacionais e maior articulação entre os profissionais da saúde e da educação básica.

A eficácia das intervenções educativas na promoção do aleitamento materno demonstra a relevância em planejar ações para os estudantes na escola, visto que este deve ser ambiente privilegiado para o aprendizado de uma vida mais saudável, a iniciar pela maneira como as crianças devem ser alimentadas desde o nascimento. Nesse processo de ensino-aprendizado, urge como essencial utilizar metodologias 
ativas e lúdicas que motivem e despertem o interesse das crianças.

Portanto, as contribuições dessa revisão remetem ao papel do enfermeiro em ampliar o debate desse conteúdo no cenário escolar visto o seu domínio técnico-científico do assunto. O ensino fundamental é uma fase em que as crianças estão sensíveis à aquisição de novos aprendizados e devido o potencial transformador da educação poderão tornarem-se agentes de mudança na sua comunidade e, talvez, dessa forma, impactar no futuro das próximas gerações no tocante ao aleitamento materno.

Por fim, destaca-se que o reduzido número de publicações encontradas sugere maiores investimentos em pesquisas nessa área, especialmente, nos estudos de intervenção, e reforça a inclusão da temática no conteúdo programático do ensino fundamental para construção de uma cultura favorável à amamentação.

\section{REFERÊNCIAS}

1. Victora CG, Bahl R, Barros AJD, França GVA, Horton S, Krasevec J, et al. Breastfeeding in the 21st century: epidemiology, mechanisms, and lifelong effect. Lancet [Internet]. 2016 [acesso em: 22 dez. 2016];387(10017):475-90. Disponível em: http://dx.doi.org/10.1016/S0140-6736(15)01024-7

2. Rollins NC, Bhandari N, Hajeebhoy N, Horton S, Lutter CK, Martines JC, et al. Why invest, and what it will take to improve breastfeeding practices? Lancet [Internet]. 2016 [acesso em: 22 dez. 2016];387(10017):491-504. Disponível em: http://dx.doi.org/10.1016/S0140-6736(15)01044-2

3. Ho Y, McGrath JM. Effectiveness of a breastfeeding intervention on knowledge and attitudes among high school students in Taiwan. J Obstet Gynecol Neonatal Nurs [Internet]. 2016 [acesso em: 22 dez. 2016];45(1):71-7. Disponível em: http://dx.doi.org/10.1016/j.jogn.2015.10.009

4. Ho Yen-Ju, Yu Chao-Chin. Attitudes of high school and vocational school students toward breastfeeding in Taiwan. J Perinat Educ [Internet]. 2014 [acesso em: 22 dez. 2016];(2):89-95. Disponível em: http://dx.doi.org/10.1891/1058$\underline{1243.23 .2 .89}$

5. Gale L, Davies N. Young people's attitudes towards breastfeeding: a survey of 13-15-yearold pupils in a south London school. Br J Midwifery [Internet]. 2013 [acesso em: 22 dez. 2016];21(3):195-201. Disponível em: http://dx.doi.org/10.12968/bjom.2013.21.3.195

6. Glaser DB, Roberts Kj, Grosskopf NA, Basch CH. An evaluation of the effectiveness of school-based breastfeeding education. J Hum Lact [Internet]. 2016 [acesso em: 22 dez. 2016];32(1):46-52. Disponível em: http://dx.doi.org/ $10.1177 / 0890334415595040$

7. Gijsen LIPS, Kaiser DE. Enfermagem e educação em saúde em escolas no Brasil: revisão integrativa da literatura. Cienc Cuid Saude [Internet]. 2013 [acesso em: 22 dez. 2016];12(4):813-821. Disponível em:

http://periodicos.uem.br/ojs/index.php/CiencCuidSaude/article/view/17618.

8. Costa GMC, Cavalcanti VM, Barbosa ML, Celino SDM, França ISX, Sousa FS. Promoção de saúde nas escolas na perspectiva de professores do ensino fundamental. Rev. Eletr. Enf. [Internet]. 2013 [acesso em: 22 dez.

2016];15(2):506-15. Disponível em: http://dx.doi.org/10.5216/ree.v15i2.15769.

9. Feldman-Winter, L. Evidence-based Interventions to Support Breastfeeding. Pediatr Clin N Am. [Internet]. 2013 [acesso em: 22 dez. 2016];60(1):169-87. Disponível em: http://dx.doi.org/10.1016/j.pcl.2012.09.007.

10. Giles M, Millar S, Armour C, McClenahan C, Mallett J, Stewart-Knox B. Promoting positive attitudes to breastfeeding: the development and evaluation of a theory-based intervention with school children involving a cluster randomised controlled trial. Matern Child Nutr [Internet]. 2015 [acesso em: 22 dez. 2016];11(4):656-72. Disponível em: http://dx.doi.org/10.1111/mcn.12079.

11. Cooper HM. Scientific Guidelines for Conducting Integrative Research Reviews. Rev Educ Res [Internet]. 1982 [acesso em: 22 dez. 2016];52(2):291. Disponível em: http://www.jstor.org/stable/1170314.

12. Critical Appraisal Skills Programme (CASP). (C Milton Keynes Primary Care Trust. 2013. All rights reserved.

13. Ursi ES, Galvão CM. Perioperative Prevention of Skin Injury: An Integrative Literature Review. Rev Lat Am 
Enfermagem [Internet]. 2006 [acesso em: 22 dez. 2016];14(1):124-31. Disponível em:

http://dx.doi.org/10.1590/S0104-11692006000100017.

14. Stillwell SB, Fineout-Overholt E, Melnyk BM, Williamson KM. Evidence-based practice, step by step: searching for the evidence. Am J Nurs [Internet]. 2010 [acesso em: 22 dez. 2016];110(5):41-7. Disponível em:

http://dx.doi.org/10.1097/01.NAJ.0000372071.24134.7e.

15. Minayo MCS. O desafio do conhecimento: pesquisa qualitativa em saúde. 14ạ ed. São Paulo: Hucitec; 2014.

16. Bottaro SM, Giugliani ERJ. Estudo exploratório sobre aleitamento materno entre escolares de quinta série do Ensino Fundamental. Cad. Saúde Pública [Internet]. 2008 [acesso em: 22 dez. 2016];24(7):1599-608. Disponível em: http://dx.doi.org/10.1590/S0102-311X2008000700015

17. Fujimori M, Morais TC, França EL, de Toledo OR, Honório-França AC. The attitudes of primary school children to breastfeeding and the effect of health education lectures.

J Pediatr (Rio J) [internet]. 2008 [acesso em: 22 dez. 2016];84(3):224-31. Disponível em:

http://dx.doi.org/10.2223/JPED.1791

18. Bottaro MS, Giugliani ERJ. Effectiveness of an Intervention to Improve Breastfeeding Knowledge and Attitudes Among Fifth-grade Children in Brazil. J Hum Lact [Internet]. 2009 [acesso em: 22 dez. 2016];25(3):325-32. Disponível em: http://dx.doi.org/ 10.1177/0890334409337248

19. Angell C, Alexander J, Hunt JA. How are babies fed? A pilot study exploring primary school children's perceptions of infant feeding. Birth [Internet]. 2011 [acesso em: 22 dez. 2016];38(4):346-53. Disponível em:

http://dx.doi.org/10.1111/j.1523-536X.2011.00484.x.

20. Spear HJ. School Nurses and Teachers: Attitudes Regarding Inclusion of Breastfeeding Education in School Curricula. J Sch Nurs [Internet]. 2010 [acesso em: 22 dez. 2016];26(2):137-46. Disponível em:

http://dx.doi.org/10.1177/1059840509350739.

21. Galvão DMPG, Silva IA. A amamentação nos manuais escolares de estudo do meio do 10 ciclo do ensino básico. Rev Enferm Ref [Internet]. 2011 [acesso em: 22 dez. 2016];serlll(4):7-16. Disponível em:

http://www.scielo.mec.pt/scielo.php?script=sci_arttext\&pid=S0874-02832011000200001\&Ing=pt\&nrm=iso\&tlng=pt. 22. Galvão DMPG, Silva IA. Abordagem da amamentação nos primeiros anos do ensino fundamental. Rev Esc Enferm USP [Internet]. 2013 [acesso em: 22 dez. 2016];47(2):477-85. Disponível em: http://dx.doi.org/10.1590/S008062342013000200029.

23. Frota MA, Casimiro CF, Bastos PO, Sousa-Filho OA, Martins MC, Gondim APS. Mothers' knowledge concerning breastfeeding and complementation food: an exploratory study. Online braz j nurs [Internet]. 2013 [acesso em: 22 dez. 2016];12(1):120-34. Disponível em: http://dx.doi.org/10.5935/1676-4285.20133890.

24. Marques ES, Cotta RMM, Priore SE. Mitos e crenças sobre o aleitamento materno. Cien Saude Colet [Internet]. 2011 [acesso em: 22 dez. 2016];16(5):2461-8. Disponível em: http://ref.scielo.org/9d5my2.

25. Tang L, Binns CW, Luo C, Zhong Z, Lee AH. Determinants of breastfeeding at discharge in rural China. Asia Pac J Clin Nutr [Internet]. 2013 [acesso em: 22 dez. 2016];22(3):443-8. Disponível em:

http://dx.doi.org/10.6133/apjcn.2013.22.3.20.

26. Mannion CA, Hobbs AJ, McDonald SW, Tough SC. Maternal perceptions of partner support during breastfeeding. Int Breastfeed J. [Internet]. 2013 [acesso em: 22 dez. 2016];8(1):4. Disponível em: http://dx.doi.org/10.1186/17464358-8-4.

27. Maycock B, Binns CW, Dhaliwal S, Tohotoa J, Hauck Y, Burns S, et al. Education and Support for Fathers Improves Breastfeeding Rates: A Randomized Controlled Trial. J Hum Lact [Internet]. 2013 [acesso em: 22 dez. 2016];29(4):48490. Disponível em: https://doi.org/10.1177/0890334413484387.

28. Godoi SC, Pol P, Matia G. A inserção da Equipe de Saúde da Família no ambiente escolar público: perspectiva do professor. Cogitare Enferm [Internet]. 2012 [acesso em: 22 dez. 2016];17(2):232-8. Disponível em:

http://dx.doi.org/10.5380/ce.v17i2.22735.

29. Buccini GS, Perez-Escamilla R, Venancio SI. Pacifier use and exclusive breastfeeding in Brazil. J Hum Lact [Internet]. 2016 [acesso em: 22 dez. 2016];32(3):NP52-NP60. Disponível em: https://doi.org/10.1177/0890334415609611.

30. Rigotti RR, Oliveira MIC, Boccolini CS, Association between the use of a baby's bottle and pacifier and the absence of breastfeeding in the second six months of life. Cien Saude Colet [Internet]. 2015 [acesso em: 22 dez.

2016];20(4):1235-44. Disponível em: http://dx.doi.org/10.1590/1413-81232015204.00782014.

31. Santos MET, Ocampo DM, Lopes MODS, Souza DOG, Folmer V. A saúde enquanto tema transversal em livros didáticos de ciências para os anos iniciais do ensino fundamental. Alexandria Revista de Educação em Ciência e

Rev. Eletr. Enf. [Internet]. 2016 [acesso em:_____];18:e1198. Disponível em: http://dx.doi.org/10.5216/ree.v18.40682. 
Tecnologia [Internet]. 2015 [acesso em: 22 dez. 2016];8(1):53-73. Disponível em: http://dx.doi.org/10.5007/19825153.2015v8n1p53.

32. Fiore EG, Jobstraibizer GA, Silva CS, Cervato-Mancuso AM. Abordagem dos temas alimentação e nutrição no material didático do ensino fundamental: interface com segurança alimentar e nutricional e parâmetros curriculares nacionais. Saude soc. [Internet]. 2012 [acesso em: 22 dez. 2016];21(4):1063-74. Disponível em:

http://dx.doi.org/10.1590/S0104-12902012000400023. 